
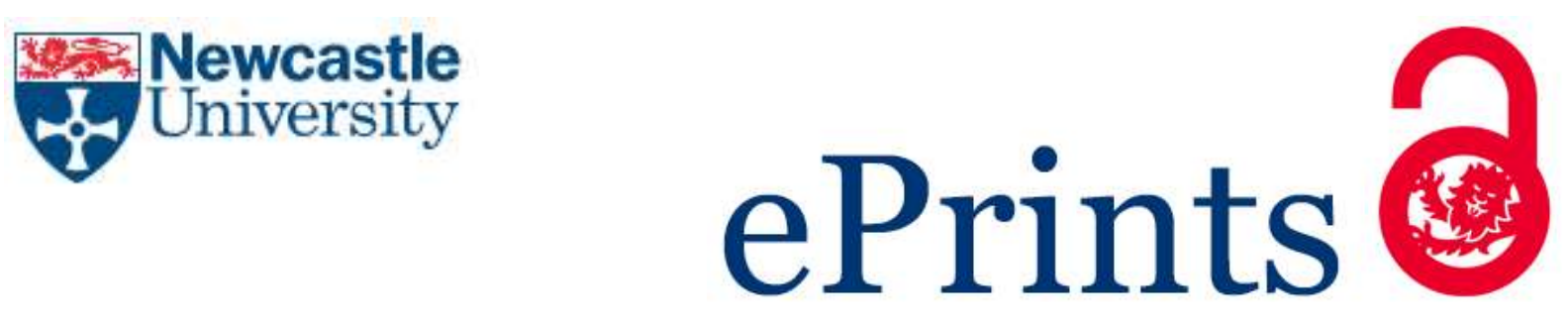

Scully JL. From "She would say that, wouldn't she?" to "Does she take sugar?" Epistemic injustice and disability. International Journal of Feminist Approaches to Bioethics 2018, 11(1), 106-124.

\title{
Copyright:
}

This is the authors' accepted manuscript of an article that has been published in its final definitive form by University of Toronto Press, 2018

DOI link to article:

https://doi.org/10.3138/ijfab.11.1.106

Date deposited:

$13 / 03 / 2018$ 


\title{
From "She Would Say That, Wouldn't She?" to "Does She Take Sugar?" Epistemic Injustice and Disability
}

Jackie Leach Scully

\begin{abstract}
Epistemic injustice is the idea that social power ensures that the knowledge of some groups is excluded from the collective epistemic resources. In this paper, I argue that there are distinctive features of disabled life that, because they shape the processes through which knowledge is gathered, evaluated, judged and disseminated, also influence the ways in which epistemic injustice is experienced by disabled people. These features include the ascription of a global epistemic incapacity to people affected by impairment. Against a background of contemporary political shifts and biotechnology innovation, the implications of epistemic injustice for disabled people are serious.
\end{abstract}

Keywords: disability and epistemic injustice, epistemic exclusion, impairment, epistemic injustice and marginalized groups

\section{Susan's story}

Susan has been profoundly deaf since childhood. She is a hearing aid wearer, and likes to use the induction loops built into some public spaces, such as theatres and cinemas, to help cut down the background noise that can make hearing speech very difficult. But this depends on the building having an induction loop fitted and properly maintained. Like many other induction loop users, Susan frequently finds that the advertised loop system is either working poorly or not working at all. Almost as often, she then has the experience of making a complaint about it only to have the 
problem denied. ("Of course there is a loop. Of course it's switched on, and of course it's working.") If she persists, she is often then met by the suggestion that she doesn't know what she's talking about: Susan, who's been wearing aids for forty-five years, is told that she misunderstands how to use the equipment properly, or asked whether, perhaps, she's just forgotten to switch on her hearing aid.

\section{The taxonomy of epistemic injustice}

Concepts relating to epistemic injustice have stimulated a lot of recent academic interest. Epistemic exclusion is the notion that social position and power align with certain forms of epistemic power, that is, power over the ways in which knowledge is accumulated within, acknowledged by, and disseminated through communities, with the result that some kinds of knowledge can be kept out of mainstream sight. There is a growing taxonomy of injustices that follows from the epistemic exclusion of marginalized social groups. They involve wronging another person in her capacity as a knower, but they operate in different ways and cause different forms of harm.

This burgeoning field of inquiry has so far concentrated on the knowledge associated with the social marginalities of gender and race (and, occasionally, also gender identity). Aside from some discussion of epistemic power processes operating in the broad context of health care (Carel and Kidd 2014), detailed considerations of what epistemic injustice might mean for disabled people are scarce: Elizabeth Barnes's recent work stands out here (Barnes 2016; see also Tremain 2017). In this paper, I provide a brief outline of what is meant by epistemic injustice, and argue that disability provides some particularly troubling and complex instances. I will examine the commonalities between disability and other social identities affected by epistemic exclusion, and then consider how disability is distinctive by virtue of the specific forms of epistemic exclusion and injustice that disabled people experience. Finally, I 
will suggest that recognizing the distorting power of epistemic injustice is of crucial importance to disability bioethics.

Ideas of epistemic injustice, agency, exclusion, oppression, and so on are grounded in a social epistemology: that is, an epistemology in which there is no such thing as an isolated, atomized "knower." For a person to perceive, describe, account for, and evaluate experience, she needs a set of epistemic tools, including "language to formulate propositions, concepts to make sense of experience, procedures to approach the world, and standards to judge particular accounts of experience" (Pohlhaus 2012, 718) drawn from her community's shared epistemic resources. To social epistemologists, knowledge is situated and particular, generated out of the concrete circumstances of groups and communities and the biographies of their members (Walker 1998). And while some experiences are shared by the majority of people, others are more specific to situations and circumstances. As a result, not all epistemic resources are held in common.

Epistemic injustice is one harmful manifestation of a broader phenomenon of epistemic exclusion. In epistemic exclusion, certain kinds of knowledge are refused admission into the general shared stock (Langton 2000). Although epistemic exclusion frequently (and, perhaps, inevitably) follows from oppressive power relations that marginalize certain social groups, it is, nevertheless, important to recognize that not all epistemic exclusion is unjust or even harmful. There are obvious reasons some kinds of knowledge need not, or should not, be included in a community's epistemic store. The knowledge may simply be irrelevant: the epistemic resource labeled "secular Jewish life" is richly stocked even without the inclusion of the knowledge called "plumbing skills," useful though the latter is. The knowledge may be considered too harmful, corrupting, or psychologically damaging; and there 
are sound ethical reasons why knowledge that is appropriate in one setting should be kept well away from others (soldiers may need to know how to kill on the battlefield but often wish profoundly not to bring that knowledge back home with them).

The two "classes" of epistemic injustice first characterized by Miranda Fricker (2007) are still the primary focus of normative analysis. What she identified as testimonial injustice is at play when mainstream society holds an identity prejudice against a specific group, and sees members of that group as having "a deflated level of credibility" (158). The result is a targeted, if unconscious, downgrading of trust in the accounts and claims of anyone from that group.

Testimonial injustice can operate through individual actions and responses. For example, Teresa tells me that she is stared at or abused on every trip she makes to the supermarket because her spina bifida means that she wears a caliper and has an unusual gait. I might not be rude enough to say so, but privately I think she must be exaggerating, or at least be hypersensitive to perfectly ordinary glances or comments. Since I personally haven't experienced anything of the kind, and I'm confident that I don't stare at disabled people, I find it hard to credit what she says. An underlying societal prejudice against disability reinforces my scepticism, and unless something happens to convince me of the truth of her claim - perhaps there's an instance of clear abuse when we happen to be out shopping together - then my lingering disbelief is likely to color our whole relationship, blocking the very kind of openness that might encourage me to think myself mistaken.

Testimonial injustice that is inflicted systematically across a range of social contexts may be even more damaging and insidious than when it is experienced at the hands of an individual - not least because it is often an undifferentiated response to members of a group, irrespective of their individual circumstances. So, in addition to 
my badly hidden scepticism, Teresa's life is also affected by a ubiquitous suspicion built into the official procedures she must go through in order to claim social support. Because she can't stand or walk for long, she is unable to work, and has to prove this to the satisfaction of the relevant authorities. Teresa is vulnerable to epistemic injustice if they refuse to accept her account of her level of disability.

Fricker's (2006) second type of epistemic injustice is hermeneutical injustice. This is defined as "having some significant area of one's social experience obscured from collective understanding owing to a structural prejudice in the collective hermeneutical resource" (100). As I described earlier, the existence of collective epistemic resources is fundamental to a social epistemology: making sense of the world requires a previously generated set of concepts, vocabulary, narratives, and so on. These resources are internalized early in life, but they originate externally in the shared community knowledge that reflects, to a degree, the gathered perspectives of the range of groups.

I say "to a degree," because the content of collective epistemic resources is inevitably skewed by power relations. The differential distribution of social and material power creates hierarchies of social position, and social position plays a major part in the kinds of experiences a person is likely to have, the knowledge and meaning derived from those experiences, and, therefore, the epistemic resources they are likely to find salient in making sense of their world (Pohlhaus 2006). At the same time, social and material power also confers epistemic authority: some people can legitimately establish and enforce epistemic practices (decide the criteria for credibility, organize the routes through which knowledge is fed into public discourse or policy debates, and so on) while others cannot. The content of any community's epistemic resources tends, therefore, to track along existing social and political 
contours. In this way, privileged groups have a disproportionate influence on the tools available to everyone, while socially marginalized groups are effectively excluded from contributing their experiences and knowledge to the collective store.

One result of this is that members of privileged groups are far more likely to have understandings of their experiences readily to hand, because their lives are socially normative. Meanwhile, the marginalization of other social groups means that the concepts, vocabulary, and narratives that are particularly salient to making sense of their lives are pushed aside.

\section{Epistemic injustice and disability}

Disabled people are commonly denied both epistemic credibility and authority, and suffer the consequences. Susan's story is one example. When it is not easily obvious to a nonuser whether a piece of assistive technology is functioning or not, it ought to be assumed that someone who is familiar with the technology and who says it isn't working is most likely to be right. This isn't what usually happens to Susan and other induction loop users, though. As a deaf person, her epistemic credibility is diminished, irrespective of the evidence or of the logic that says her knowledge is probably trustworthy.

Susan's is an example of disability-specific testimonial injustice played out on an individual level. A case of more systemic epistemic injustice is provided by what is known as the central disability paradox: the extensive body of empirical evidence suggesting that disabled people can differ markedly from nondisabled people in their assessments of the quality of life with impairment. Empirically, disabled people tend to describe a "quality" of life only slightly below what nondisabled people report having. The important point here is that this suggests that when nondisabled people think about life with an impairment, they tend to imagine it as entailing a much worse 
quality of life than disabled people say they experience (Amundsen 2005, 103; Ubel et al. 2005; Edwards 2013). I want to emphasize that this is not always the case, especially not for more recently disabled people whose impairment constitutes a significant loss and who are still struggling to adapt to their changed circumstances. Nevertheless, we have to take seriously the evidence of disabled people saying that life with an impairment is not necessarily unbearable or tragic, and may even be a substantial and positive part of their identity.

The two most common responses by nondisabled people to these claims both have a quality of "She would say that, wouldn't she?" The first is to say that the perceptions of disabled people (and particularly those who have been disabled since birth) are inevitably distorted by their inbuilt epistemic limitation. Since they haven't experienced any alternative, they can do no other than evaluate their state as normal. Disabled people rank their quality of life as highly as they do simply because they don't know any better. A second response draws on the idea of adaptive preferences: a change in a person's desires as a response to constrained options, and where the shift appears to be from preferring an objectively better state toward a worse one. Adaptive preferences are a necessary psychological defense against acknowledging the true awfulness of a state that can't be changed (Elster 1983; Nussbaum 2001).

But as Barnes (2016) and others have pointed out, the argument from adaptive preferences is itself based on the newly preferred or accepted option (in this case, disability) being objectively worse than the previous state. In this view, to be disabled is to be worse off, and so the argument from adaptive preferences at one stroke renders invalid the testimony of some disabled people that they aren't (129-35). In these exchanges, the nondisabled commentator remains committed to the view that if what she thinks differs from disabled people's accounts, then it is the latter who must 
be mistaken or misguided. This is classic testimonial injustice: because disabled people are subject to identity prejudice, they are also subject to diminished credibility. Their knowledge is dismissed because it is assumed that their perceptions are inherently untrustworthy and possibly self-serving in a way that those of nondisabled people are not.

As well as testimonial injustice, disabled people also experience its hermeneutic counterpart. Living with various kinds of impairment results in the accumulation of a wealth of quite distinctive knowledge. A wheelchair user, for instance, will not only be familiar with technical data about different types of wheelchair or how to finance its purchase or repair; they will also have embodied knowledge about handling their wheelchair in different environments and weather conditions, about how other people respond to wheelchairs and wheelchair users, about the physical effects of using a wheelchair, and so on. It is specialized knowledge formed by a distinctive set of experiences, and it generally fails to enter the routinely available, collective epistemic resources.

Now, it could be argued that there is no real problem with that, since the collective store has no requirement to incorporate routinely knowledge that is specific to such a minority population. One possible response is to question just how small a minority we are talking about. It is currently estimated that there are 1.2 million wheelchair users in the United Kingdom (NHS England n.d.). This is hardly an insignificant number: it's larger than the total number of people attending Anglican church services on a typical Sunday, for instance (Sherwood 2016).

A second point is that only some minority populations are actively discriminated against. Disability is not alone in being an unusual embodied experience. Professional ballet dancers, for example, are also a minority, and details 
of the embodied lives of the corps de ballet would be equally alien to most people. But there is an important ethical difference between experiential knowledge that happens to be accumulated by only a few people, and is represented in the cultural resources proportionately, and the epistemic capital of social groups that are systemically and systematically suppressed. The former case is probably an example of the (relatively) benign epistemic exclusion I mentioned earlier: the knowledge just isn't relevant to most people and, so, doesn't get wide uptake. But ballet dancers are not routinely discriminated against - they may suffer various professional unfairnesses, but no more than anyone else. Moreover, and to repeat the point about hermeneutic injustice, the community of ballet dancers shares and generally has access to a pool of knowledge relevant to their distinctive experiences of buying pointe shoes and eschewing chocolate. (I'm guessing here.) And, finally, we should also be asking who decides (that is, who has the power to decide) where to set the cutoff point between "knowledge relevant to most of us" and "this is of minority interest only."

\section{Effects}

Both testimonial and hermeneutic epistemic injustice cause harm to those on the receiving end. Testimonial injustice results from the unwarranted denial or devaluation of someone's epistemic credibility. ${ }^{1}$ The consequences of this denial are extensive, including the subtle and more overt downgrading of the weight given to groups' perspectives, opinions, and needs, and the perpetuation of toxic stereotypes. Most fundamentally, a person experiencing testimonial injustice is not being treated as an agent capable of contributing to knowledge that is, as Fricker (2007) observed, equivalent to being treated as incapable in the capacity for reason - a function central to many of our ideas about human personhood (44). People suffering testimonial 
injustice are, therefore, being denied equal moral status with other humans within their community, and this is an important wrong even if the epistemic injustice is apparently the only way in which such status is being denied. ${ }^{2}$ Having their claims and accounts epistemically downgraded is guaranteed to unsettle a person's trust in the epistemic and moral value of their own narratives and judgments and, if internalized, their confidence in their overall agential capacity. This is an especially potent harm to disabled people who, as I discuss later, very often have their status as persons of the same moral value as all other persons called into question.

Hermeneutic injustice, which involves excluding the knowledge of stigmatized groups from the collective epistemic resources, is also a wrong to someone's capacity as a knower, but in a different way. If the result of epistemic exclusion is that a wheelchair user is deprived of useful knowledge about how to live, then they suffer a wrong. Consider a person who has just had a spinal cord injury, and knows no other people who are experienced wheelchair users. Or, perhaps, a child with a mobility impairment is raised by parents who believe very strongly that, in order for her to succeed in the outside world, she needs to be kept away from other wheelchair users so that she doesn't begin to think of herself as "handicapped" in any significant way. In both cases, the disabled person does not have access to “wheelchair user knowledge" through a community of peers (because they don't know any), and they don't have access to it via the collective resources (because it isn't there). As a result, they may well be unable to make sense of important areas of their personal and social lives. They are deprived of significant routes to selfunderstanding, self-confidence, and trust in themselves as epistemic agents, with consequences for their sense of identity and of moral and political agency. A person who does not have to hand the language and concepts that give a framework of 
meaning to her everyday experiences will also lack easily available ways of formulating and ethically justifying her choices and goals, making moral judgements, articulating her experiences as just or unjust, and so on. In other words, through its effect on important features of moral agency and identity, an impoverished epistemic capacity is also partway to producing impoverished moral capacity as well.

The ongoing academic analysis of testimonial and hermeneutic injustice has rightly focused on marginalized communities, in part to correct historical neglect and to prevent the continuation of that harm into the present. It should not be forgotten, though, that epistemic exclusion also causes harm to the larger (mainstream) epistemic community. The wider community is dependent for its knowledge on the collective epistemic resources. If there are gaps, then, the resources are impoverished, and because the knowledge that is present is disproportionately skewed to the perceptions of the more powerful group (in this case, nondisabled people), then these resources are structurally distorted as well. Even if its members are oblivious to it, the wider community is harmed if its epistemic resources could be richer and more accurate than they actually are. The capacity for empathy might be affected, for example. If it requires the ability to project oneself imaginatively into another person's shoes (Mackenzie and Scully 2007), then not having adequate knowledge of the other's circumstances means that imaginative projections into that other life are much more likely to be flawed, and so also to compromise the ability to empathize effectively overall.

But although unwarranted epistemic exclusion can be considered a harm to the wider community, it is not an injustice. The majority is not disadvantaged in the same way that an individual disabled person would be. Indeed, those in the wider community who are flourishing under the status quo of their limited knowledge might 
reject my assertion that they are harmed by the impoverishment of their epistemic resources. They might want to say those resources are fine just as they are since they themselves continue to get along perfectly well with no sense of epistemic failure or lack. (I would argue they are mistaken, and that being part of a community fragmented by epistemic as well as material exclusion and unacknowledged injustice is harmful to all its members, including those currently on top; but that's a wider discussion.)

Moreover, although the collective can act to ameliorate the problem of epistemic exclusion, it can also, even unwittingly, exacerbate it. Suppose that, despite hermeneutic exclusion, a disabled person is perfectly able to understand and articulate her experience. Nevertheless, what she says about it may be rejected by her audience in the wider community, not because they don't find her credible (as would be the case with testimonial injustice), but because they are simply unable to make sense of what she's saying. Their own comprehension is underequipped due to the failings in their epistemic resources (Dotson 2012, 32). Take the terminology of "ableism" and "disablism" that, in analogy with racism and sexism, has been used within disability scholarship to describe the phenomenon of systemic prejudice against disabled people (Campbell 2008). Without the experiential and theoretical backgrounding that gives insight into what it meant by those words, they may be dismissed as incomprehensible or unnecessary. This has been described as contributory injustice, and it is caused by what Gaile Pohlhaus (2012) characterized as willful hermeneutical ignorance. The "willful" is justified because people who engage with disabled knowledge and find it alien or implausible have the option of recognizing their own epistemic limitations ${ }^{3}$ and doing whatever is necessary to correct for them. Instead of having the humility to recognize that they don't know quite as much as they think they do, in contributory 
injustice members of the dominant group compound the problem by insisting on trying to comprehend other groups' epistemic claims within the boundaries of their own preexisting frameworks of understanding and judgment, refusing to do the work of open self-critique and, where necessary, adjustment.

\section{Disability is distinctive}

Some aspects of the way epistemic injustice operates apply to any socially oppressed group. Alongside that, every group will also have some distinct features that set its experience of epistemic exclusion apart from others'. In the following section, I outline some aspects of disabled life that shape the processes through which knowledge is gathered, evaluated, judged, and disseminated within and between different communities of disability. ${ }^{4}$

\section{a. Diversity of impairment}

The sheer diversity of disability places distinctive constraints on the degree to which knowledge can usefully be generalized from one type of impairment to another. Some experiences are so widely shared they can be taken as characteristic of disabled knowledge: knowing what it is like to be stared at in public because of your physical or behavioral anomaly, for example, or being routinely excluded from supposedly public events because the venue is inaccessible to you. But an important differential is introduced by the fact that some experiences of people with one kind of impairment (such as wheelchair users) won't be shared by those with a different one (limited vision, for example), even though both are contained within the category of "disabled." The knowledge here isn't evenly distributed: there is no reason a blind person should know any more than a nondisabled person about buying motorized wheelchairs. At the same time, the separation isn't absolute, and there are aspects of life with an impairment, and, therefore, kinds of knowledge, that are partially shared. 
So, blind people know little about wheelchairs, while wheelchair users probably don't know much about guide dogs, but both visually and mobility impaired people are likely to find unfamiliar rooms stuffed with close-packed furniture equally challenging, although for different reasons.

\section{b. Isolation from the epistemic community}

Since the late twentieth century, many Western societies have undergone profound changes in attitudes toward disability and disabled people. Preeminently but not solely in the United Kingdom and the United States, there has been a shift toward social policies that mainstream disability in education, housing, and employment. ${ }^{6}$ Mainstreaming means that children with impairments are now far more likely to live with their families and be educated alongside nondisabled children instead of in specialized schools. Disabled adults are more likely to be living independently and working in regular jobs alongside nondisabled colleagues rather than in residential adult care. ${ }^{7}$ Most of us would see this decline in segregation of disabled people as overall a good thing.

But one consequence of mainstreaming is that it is now less common for disabled people to be part of a physical community of others, or even to know another person, with the same or similar impairments. Again, there are many reasons this is generally better for those individuals and for the wider communities in which they now have the opportunity to play a fuller role. However, it also means it is harder for disabled people to find the kind of network that holds minority knowledge about living with a particular impairment. Women and ethnic minorities are epistemically marginalized from the dominant group of white men, but they do not usually live in isolation from each other and don't normally have to create their own understandings 
de novo, because a community within which their marginalized knowledge is supported already exists. $^{8}$

A particularly contentious example is the experience of the signing Deaf ${ }^{9}$ community, where there is considerable ambivalence about the benefits of educational mainstreaming. According to one estimate, there were seventy-five schools for the deaf in the United Kingdom in 1982 (Moore 2008); by 2010, this had fallen to twenty-three (Consortium for Research into Deaf Education 2011). Historically, schools for the deaf and Deaf Clubs were the places where deaf children learnt sign language, were exposed to Deaf culture, and absorbed the embodied knowledge of the Deaf world. Currently, there is a lot of anxiety within the Deaf world about how to maintain Deaf language and culture in a context where deaf people are more scattered through the hearing world and less often come together to form a critical mass (Padden and Humphries 2005; Bauman 2008; Lane et al. 2011).

\section{c. Systemic exclusion in health and social care}

When individual members of a dominant group treat marginalized others unjustly, it's still possible for them to reach a point where they realize what they have done, and try to correct it and make amends. Perhaps, you have been a friend of Susan's for years, and privately wish she'd stop banging on about the inadequacy of induction loop provision. She clearly has a chip on her shoulder about it, and you're sure it can't be nearly as bad as she makes out. But then your own father develops age-related hearing loss. He starts using hearing aids, and now he too complains about the lack of induction loops in public spaces. Perhaps Susan wasn't making a fuss about nothing after all? Feeling embarrassment and remorse, you acknowledge your crassness and resolve in future to be a little more humble in the way you respond to the claims of disabled people. 
But however worthy your personal attempt to become a more "virtuous knower," it will probably make no real difference to most disabled people's lives (other than easing tension between you and your good friend Susan) if the policies, practices, and epistemological structures of the rest of society remain unchanged. Individuals are generally more epistemically flexible than institutions and organizations, and this point carries particular force for any group that has more than average exposure to professional expertise. Disabled people and their families generally need medical or social care at some point in their lives; these needs can be minor, but they can also be extensive and lifelong. Whether the context is a consultation with a medical professional or an application for social security payments, the institutions of health and social care tend to have rigid expectations of the language, narratives, forms of evidence, and so on that they are prepared to take seriously. For a disabled person's knowledge to be treated as valid in these professional contexts, she must be sure to communicate it using the tools considered appropriate by the institution. Many disabled people will be unable or unwilling to do so. They may not be comfortable with the technical language (or if they are, may come across as suspiciously knowledgeable for a nonprofessional); they may express themselves too emotionally or rely too much on anecdote; or it could be that they know perfectly well how to do it, but are fed up of playing that particular game. However sympathetic an individual clinician or social worker, the institutions of health and social care hold enormous structural epistemic privilege, and there is always a risk that what a disabled person says will be dismissed as biased, exaggerated, limited, or incomprehensible. The key point here is that the highly specialised epistemological regimes of health and social care can be omnipresent in 
disabled people's everyday lives in a way that is less often true for nondisabled people.

\section{d. Global epistemic incapacity: "Does she take sugar?"}

The philosopher and disability scholar Adrienne Asch remarked on the way that impairment is a single trait that can overwhelm everything else we know about a person and the life they lead (or, in the case of prenatal testing, the life they might go on to lead) (Asch and Wasserman 2005). Disabled people often comment that others “don't look past the disability." In the epistemic arena, this plays out in the ascription of what I call global epistemic incapacity. The fact of impairment by itself is taken to render someone incapable of being a source of reliable knowledge, irrespective of whether the impairment itself might reasonably be expected to do so.

Although this phenomenon is not unique to disability, the degree to which it happens is. ${ }^{10}$ When women are considered epistemically flawed, the rationale isn't usually that they have an intrinsic cognitive impairment but because of their disadvantaged social position, limited education, or lack of wider world experience. Similarly, a black person's account of discrimination is more likely to be dismissed because of a belief that she is resentful of white privilege and hypersensitive to minor slights than because she is thought to be so epistemically incompetent she mistakenly sees discrimination where there is none.

This means that for gender, ethnicity, sexual identity, and so on, the feature that is the "reason" behind someone's social marginalization is not precisely the same feature that justifies their epistemic exclusion. Women are marginalized from the mainstream contours of power and authority because of their gender; it isn't simply because of that identity that their knowledge is discounted, though, but because some real or imagined consequence of being a woman leads to the conclusion that their 
accounts are not worth real attention. Black communities are not considered epistemically compromised because of their skin color, but because their ethnicity has downstream effects (it's thought) on what they can know. In both cases, it's a contingent rather than intrinsic epistemic inferiority (though no less toxic for that). ${ }^{11}$

By contrast, disability is often understood as global impairment - that is, that having one kind of impaired functionality necessarily compromises the ability to do all sorts of other things as well, up to and including understanding one's own environment, preferences, and so on. Many disabled people can give examples from their lives of "Does she take sugar?" occasions. The phrase references the moment when a nondisabled person directs a question not at a disabled person herself but at her companion, clearly believing that, say, a mobility impairment renders her incapable of knowing or communicating how sweet she likes her tea. (So familiar are these occasions that Does He Take Sugar? was used as the title of BBC Radio 4's flagship disability program from 1977 to1998.) Similarly, someone with a visual impairment may be spoken to with an ostentatiously simplified vocabulary, or a deaf person assumed to be ignorant of current political events. In other words, an impairment that ostensibly has no impact on a person's epistemic abilities is treated as if it did.

One note of caution: earlier, I was critical of the tendency to conflate the enormous diversity of impairment under the umbrella heading "disability," and I don't want to do the same thing here. The complicating factor in this argument is that some learning disabilities, severe developmental disorders, and mental health problems genuinely do compromise a person's ability to comprehend their world (or, perhaps, more accurately, their ability to comprehend the world and communicate it in the same way as the majority). These impairments present genuine cognitive and 
communicative barriers to making use of shared epistemic resources or providing an account of one's life that others will find credible. Nevertheless, they can mostly be distinguished from impairments that have little or no obvious effect on perception, cognition, or communication, and that, therefore, have no obvious epistemic consequences.

\section{e. Bad bodies = bad knowledge}

Structural epistemic inequalities result in the experiences and insights of marginalized groups being largely obscured from majority view, but the sheer fact of exclusion need not imply any strongly negative opinion about the knowledge itself. The value ascribed to epistemic resources is a reflection of the ontological value attributed to the community that holds them: whether the community is thought to be worth having determines whether that community's knowledge is considered worth having as well. If a community is simply not considered to be as valuable as others, then there is something about its members that is intrinsically wrong. Women or members of despised ethnic groups are not usually considered intrinsically wrong, even by sexists or racists. This is a broad claim, and it must be acknowledged that at least some men (and a few women) do view women as intrinsically inferior to men, but I don't think they believe that there is an intrinsic wrongness about being a woman such that the world would be better off without them (for one thing, the human species would have a short future in their absence). The situation with racism is more complicated, but, on the whole, although racists think blacks are inferior to whites, only a minority think they shouldn't exist at all. Rather, the racist thinks that blacks should know their place, or that they should be somewhere else, like not in my neighborhood. ${ }^{12}$

Disability is different. Almost universally, being disabled is considered not merely an undesirable or problematic state of being, but one where something has 
gone awry. The English language reveals this: to be dis-abled or im-paired is to be defined as a normative negation, in a way that women, black and ethnic minorities, and so on are not. The equivalent would be to refer to women as dis-gendered, and the fact that this sounds weird underlines how the construction, and the moral texture, of the categories of "women" and "disabled" also differ fundamentally.

Believing that a disabled person's state of being is at best regrettable and to be avoided if at all possible, and at worst fundamentally wrong, can very easily lead to the conclusion that their knowledge, particularly knowing what it is like to be them, is irrelevant (what could be epistemically valuable about an ontologically flawed state that we hope to get rid of?) or else, in a more metaphysical sense, is contaminated by the suffering associated with impairment: the knowledge is not just valueless, but actively repellent. (Or, as a colleague once said to me about my research, "Why do you want to go into something so yucky?”)

\section{The (bio)ethical importance of disability epistemic injustice}

The various forms of epistemic exclusion and injustice that recent scholarly literature identifies are hardly new, even if the rapid inflation of the taxonomy at the moment makes it seem so (Kidd et al. 2017). In some ways, however, many subtle variants of testimonial, epistemic, contributory, or other injustice are characterized, the central moral point has been made: excluding a marginalized group's knowledge from the common epistemic stock is a persistent and powerful way to ensure that its members stay pushed to the edges of social life. In this final section, however, I want to indicate why there are certain novel features of the contemporary world that mean disabled people are increasing likely to suffer from distinctive effects of epistemic injustice, and why this is relevant to bioethics. 
First, there is evidence that the past half-century of progress toward equality for disabled people is stalling, or even actively regressing. Since the economic crash of 2008 and the rise in conservative and rightwing politics in parts of the West, disability scholars and activists have been dismayed to note an increasing number of policies that disproportionately harm disabled people, including what in the United Kingdom are called "austerity" measures that cut funding for measures that support disabled children and adults (Williams-Findlay 2011) to the extent that in 2017 the government of the United Kingdom was strongly criticized by the United Nations Committee on the Rights of Persons with Disabilities for its inconsistent and patchy approach to protecting disability rights and its failure to audit the impact of its austerity policies on disabled people (Jones et al. 2017). Alongside that is a documented rise in reports of hate crimes targeting disabled people (although these figures have to be interpreted with care, since the apparent rise could also reflect a greater willingness to report it as well as a genuine increase in cases) (Briant et al. 2013; Cross 2013). These and other observations suggest that the trajectory of slow but steady movement toward the goal of the inclusion and equality of disabled people may not be as inevitable as we have wanted to believe.

Second, these social and political shifts are happening at the same time as rapid advances in biomedicine, and especially genomics, that offer powerful methods of identifying, selecting, and directly altering ("editing") the genetic variations associated with physical and intellectual impairments (Nuffield Council on Bioethics 2016). ${ }^{13}$ It is important to emphasize that neither the political nor the technological transformations can or should be taken as straightforward indicators that societies are turning to a modern version of eugenics. Nevertheless, it would be naïve not to ask 
whether these shifts help to reinforce the view that all forms of unusual embodiment are both an unalloyed tragedy and a burden to the family and the state.

The discipline of bioethics has always had a particularly close, and often contentious, relationship with disability. One of bioethics' primary roles is to evaluate the ethical permissibility of novel health care interventions and policies. Typically, this requires making a judgment about whatever it is the intervention or policy targets: for example, weighing up whether the quality of life of an individual with a particular impairment is sufficiently poor that prenatal selection to prevent the birth of that individual is morally justifiable. The discussion of epistemic injustice I have given here suggests that it is not safe to assume that the resources bioethicists draw on to make such evaluations are up to the job. Indeed, there has been longstanding critique, especially but not solely by feminist bioethicists, that the experiential and empirical knowledge of disabilities that bioethics brings to its deliberations is inadequate. There are numerous examples of the consequences this kind of epistemic gap can have for ethical thinking, responsible innovation, and health care policy.

A particularly notorious example is so-called "choosing deaf/disabled babies." An early case, in which two women with genetic deafness expressed a preference for a deaf child, and actively increased the chances of getting one by choosing a genetically deaf sperm donor (Mundy 2002), has provided material for an impressive amount of bioethical publications, presentations, and teaching (see, e.g., Levy 2002; Savulescu 2002; Spriggs 2002; Wilkinson 2010; Fahmy 2011; Scully 2011). Ultimately, that case also provided part of the motivation for insertion of what is now section 14(4)(9) in the U.K. Human Fertilisation and Embryology Act (2008) that prevents licenced fertility clinics using gametes or embryos for pregnancy if they have genetic "abnormalities" associated with a risk of "serious physical or mental 
disability." As critics have noted, bioethical analyses have tended to make assumptions about the motivations behind these apparently counterintuitive preferences, and also neglected to examine how often an expressed preference would actually be acted upon (Scully 2008; Emery et al. 2010) What little evidence there is suggests that deaf people who express a preference for a deaf child would not necessarily actually wish to take measures to ensure they got one (Middleton et al. 1998; Middleton et al. 2001; Stern et al. 2002). Moreover, whether or not the reasoning behind the preferences is judged to be morally acceptable, the failure to make any effort to find out what that reasoning actually is - to plug the obvious epistemic gap - is to treat the knowledge of that particular community with disrespect. This would still, therefore, be an injustice, even if it had not contributed to the legal provision that some deaf and disabled people find discriminatory (Emery et al. 2010).

Similarly, in a recent project in which people with spinal cord injury discussed their needs and interests for the benefit of engineers developing sophisticated assistive technologies, participants emphasized that in contrast to what the engineers might presume, being able to walk again was not the "holy grail." Sensory capacity, for example, often took higher priority. This information was not readily available to the engineers through their own experiences, nor through the collective epistemic resources of their wider culture and profession. Without talking with people affected by spinal cord injury, large amounts of time and money could be invested in developing technologies that ignore the actual needs of the supposed beneficiaries because of lack of knowledge. ${ }^{14}$ And this, too, is an avoidable injustice. There are many other examples. 
I have argued elsewhere (Scully 2008) for a disability bioethics that starts from a deeper knowledge of what it is like to live with, or be part of a family affected by, disability. The expansion of our epistemic resources on disability becomes an ethical requirement. However, as this paper shows, the barriers against doing so are very high, and also very resilient (Dotson 2014), perpetuated as they are along with the similarly resilient structures of social privilege and power. Part of the ethical task, then, is to identify and as far as possible remove the mechanisms that exclude the epistemic resources of disabled bodies from their communities' bodies of knowledge.

\section{NOTES}

1. "Unwarranted" is an important qualifier here. There are, of course, many situations in which it makes perfect sense not to confer full credibility. Someone may lack specialist or technical knowledge in circumstances where it is essential, or may give other evidence of not having relevant experience, deliberately lying, being mistaken or deluded, and so on.

2. Given the complex social and political forces that generate the groups subject to testimonial injustice, it is unlikely to be.

3. I don't mean by this that the claims of disabled people (or another marginalized group) should always be believed, however implausible. Not applying similarly rigorous standards of critical examination to all groups is just as discriminatory, and in the long term probably as disadvantageous, as rejecting the views of marginal groups tout court.

4. This does not mean that other marginalized groups are homogeneous, only that in this section I focus on distinctive features of impairment and disability groups. 
5. For some critics, this diversity calls into question the validity of the umbrella term "disability or "disabled people," however useful it is politically and practically.

6. Policies that are not always followed through in practice, or given the political and economic support necessary if they are to be successful.

7. If they are employed at all. Numerous studies confirm that employment rates for people with disabilities are well below those of the nondisabled population (e.g., the World Report on Disability [World Health Organization and World Bank 2011]) gives average employment rates of 52.8 percent for men with disability and 19.6 percent for women with disability, compared to 64.9 percent for nondisabled men, and 29.9 percent for nondisabled women.

8. I should add that this feature also applies to LBGTQ individuals, although how much is dependent on context. In particular, the spread of global media communications means that detailed, positive representations of multiple ways of being lesbian, queer, transgender, and so on are increasingly available to individuals who may not know any other LBGTQ people in real life (or think they don't). The same is not true for disabled people, since there is compelling evidence that they are significantly underrepresented in popular entertainment media such as television and film.

9. I'm using the convention in which "deaf" refers to audiological deafness, while "Deaf" refers to the sociolinguistic group characterized by the use of signed languages.

10. In stereotype research, there is a similar concept of "spillover" that refers to a stereotype's ability to affect domains other than those specifically targeted by it. 
11. Of course there are sexists who dismiss women as unreliable epistemic agents on the grounds that they are globally inferior to men, and racists who act similarly about black people, but I would argue these are extreme views.

12. The situation with religious prejudice is more complicated. What is intrinsically wrong here is the belief or adherence to the faith, not an embodied feature like sex or skin color. In some faith groups, like Christianity, conversion allows a "wrong" person to become a "right" one in an instant. Religious prejudice is further complicated by the way that faith adherence tracks with ethnic or national identities.

13. Here, I suggest, is another important way in which disability and other marginal identities differ. However sexist or racist some societies are, there is no evidence of widespread enthusiasm for technologies that aim to reduce the number of women or ethnic minorities.

14. I thank Sara Goering for this example.

\section{REFERENCES}

Amundsen, Ron. 2005. "Disability, Ideology, and Quality of Life: A Bias in Biomedical Ethics." In Quality of Life and Human Difference: Genetic Testing, Health Care, and Disability, ed. David Wasserman, Jerome Bickerbach, and Robert Wachbroit, 101-24. New York: Cambridge University Press.

Asch, Adrienne, and David Wasserman. 2005. "Where Is the Sin in Synecdoche? Prenatal Testing and the Parent-Child Relationship." In Quality of Life and Human Difference: Genetic Testing, Health Care, and Disability, ed. David 
Wasserman, Jerome Bickerbach, and Robert Wachbroit, 172-216. New York: Cambridge University Press.

Barnes, Elizabeth. 2016. The Minority Body: A Theory of Disability. Oxford: Oxford University Press.

Bauman, H-Dirksen L. 2008. Open Your Eyes: Deaf Studies Talking. Minneapolis: University of Minnesota Press.

Briant, Emma, Nick Watson, and Gregory Philo. 2013. "Reporting Disability in the Age of Austerity: The Changing Face of Media Representation of Disability and Disabled People in the United Kingdom and the Creation of New 'Folk Devils." Disability and Society 28 (6): 874-89.

Campbell, Fiona Kumari. 2008. "Refusing Able(ness): A Preliminary Conversation about Ableism.” M/C Journal 11 (3). <http://journal.mediaculture.org.au/index.php/mcjournal/article/view/46

Carel, Havi, and Ian James Kidd. 2014. "Epistemic Justice in Healthcare: A Philosophical Analysis." Medicine, Health Care and Philosophy 17 (4): 52940.

Consortium for Research into Deaf Education. 2011. “CRIDE Report on 2011 Survey on Education Provision for Deaf Children in England." http://www.batod.org.uk/content/resources/survey/cride-2011/CRIDE2011.pdf

Cross, Merry. 2013. "Demonised, Impoverished and Now Forced into Isolation: The Fate of Disabled People Under Austerity.” Disability and Society 28 (5): 71923.

Dotson, Kristie. 2012. “A Cautionary Tale: On Limiting Epistemic Oppression.” Frontiers: A Journal of Women's Studies 33 (1): 24-47. 
Dotson, Kristie. 2014. “Conceptualizing Epistemic Oppression.” Social Epistemology 28 (2): 115-38.

Edwards, Claire. 2013. "The Anomalous Wellbeing of Disabled People: A Response.” Topoi 32 (2): 189-96.

Elster, Jon. 1983. Sour Grapes: Studies in the Subversion of Rationality. Cambridge, UK: Cambridge University Press.

Emery, Steven D., Anna M. Middleton, and Graham H. Turner. 2010. "Whose Deaf Genes Are They Anyway? The Deaf Community's Challenge to Legislation on Embryo Selection.” Sign Language Studies 10 (2): 155-69.

Fahmy, Melissa Seymour. 2011. "On the Supposed Moral Harm of Selecting for Deafness.” Bioethics 25 (3): 128-36.

Fricker, Miranda. 2006. "Powerlessness and Social Interpretation.” Episteme: A Journal of Social Epistemology 3 (1-2): 96-108.

Fricker, Miranda. 2007. Epistemic Injustice: Power and the Ethics of Knowing. Oxford: Oxford University Press.

Human Fertilisation and Embryology Act 2008. http://www.legislation.gov.uk/ukpga/2008/22/contents

Jones, Antonia, Wendy Wilson, Tim Jarett, et al. 2017. The UN Inquiry into the Rights of Persons with Disabilities in the UK. London: House of Commons Library. Briefing paper 07367, March 27. http://researchbriefings.parliament.uk/ResearchBriefing/Summary/CBP7367\#fullreport 
Kidd, Ian James, José Medina, and Gaile Pohlhaus, Jr. eds. 2017. The Routledge Handbook of Epistemic Injustice. New York: Routledge.

Lane, Harlan, Richard C. Pillard, and Ulf Hedberg. 2011. The People of the Eye: Deaf Ethnicity and Ancestry. Oxford: Oxford University Press.

Langton, Rae. 2000. "Feminism in Epistemology and Objectification.” In Cambridge Companion to Feminism in Philosophy, ed. Miranda Fricker and Jennifer Hornsby, 127-45. Cambridge, UK: Cambridge University Press.

Levy, N. 2002. “Deafness, Culture, and Choice.” Journal of Medical Ethics 28 (5): 284-85.

Mackenzie, Catriona, and Jackie Leach Scully. 2007. "Moral Imagination, Disability and Embodiment." Journal of Applied Philosophy 24 (4): 335-51.

Middleton, Anna, Jenny Hewison, and Robert Mueller. 1998. “Attitudes of Deaf Adults Towards Genetic Testing for Hereditary Deafness.” American Journal of Human Genetics 63 (4): 1175-80.

Middleton, Anna, Jenny Hewison, and Robert Mueller. 2001. "Prenatal Diagnosis for Deafness - What Is the Potential Demand?" Journal of Genetics Counseling 10 (2): $121-31$.

Moore, E. 2008. “A Lesson from History.” British Association for Teachers of the Deaf Magazine. March 2008, 4-6

Mundy, Liza. 2002. “A World of Their Own.” Washington Post Magazine, March 31. https://www.washingtonpost.com/archive/lifestyle/magazine/2002/03/31/aworld-of-their-own/abba2bbf-af01-4b55-912c-85aa46e98c6b/ 
NHS England. n.d. "Improving Wheelchair Services." https://www.england.nhs.uk/ourwork/pe/wheelchair-services/

Nuffield Council on Bioethics. 2016. Genome Editing: An Ethical Review. London: Nuffield Council on Bioethics. http://nuffieldbioethics.org/wpcontent/uploads/Genome-editing-an-ethical-review.pdf

Nussbaum, Martha C. 2001. “Symposium on Amartya Sen's Philosophy 5: Adaptive Preferences and Women's Options." Economics and Philosophy 17: 67-88

Padden, Carol A., and Tom Humphries. 2005. Inside Deaf Culture. Cambridge, MA: Harvard University Press.

Pohlhaus Jr., Gaile. 2006. “Knowing (with) Others.” Social Philosophy Today 22: 187-98.

Pohlhaus Jr., Gaile. 2012. "Relational Knowing and Epistemic Injustice: Toward a Theory of Willful Hermeneutical Ignorance." Hypatia 27 (4): 715-35.

Savulescu, Jonathan. 2002. 'Deaf Lesbians, 'Designer Disability,' and the Future of Medicine.” BMJ 325: 771-73.

Scully, Jackie Leach. 2008. Disability Bioethics: Moral Bodies, Moral Difference. Lanham, MD: Rowman \& Littlefield

Scully, Jackie Leach. 2011. "Choosing Disability, Symbolic Law, and the Media.” Medical Law International 11 (3): 197-212.

Sherwood, Harriet. 2016. "Church of England Weekly Attendance Falls Below $1 \mathrm{~m}$ for First Time.” The Guardian, January 12. https://www.theguardian.com/world/2016/jan/12/church-of-englandattendance-falls-below-million-first-time 
Spriggs, Merle. 2002. "Lesbian Couple Create a Child Who Is Deaf Like Them." Journal of Medical Ethics 28: 283. http://jme.bmj.com/content/28/5/283

Stern, S.J., K.S. Arnos, L. Murrelle, et al. 2002. "Attitudes of Deaf and Hard of Hearing Subjects Towards Genetic Testing and Prenatal Diagnosis of Hearing Loss.” Journal of Medical Genetics 39 (6): 449-53. http://jmg.bmj.com/content/39/6/449

Tremain, Shelley. 2017. "Knowing Disability, Differently.” In Routledge Handbook of Epistemic Injustice, ed. Ian James Kidd, José Medina, and Gaile Pohlhaus Jr., 175-84. New York: Routledge.

Ubel, Peter A., George Loewenstein, and Norbert Schwarz, et al. 2005.

"Misimagining the Unimaginable: The Disability Paradox and Health Care Decision Making." Health Psychology 24 (4): S57-S62

Walker, Margaret Urban. 1998. Moral Understandings: A Feminist Study in Ethics. New York: Routledge

Wilkinson, Stephen. 2010. Choosing Tomorrow's Children: The Ethics of Selective Reproduction. Oxford: Oxford University Press

Williams-Findlay, Robert. 2011. "Lifting the Lid on Disabled People Against Cuts." Disability and Society 26 (6): 773-78.

World Health Organization and World Bank. 2011. World Report on Disability. Geneva, CH: World Health Organization. http://www.who.int/disabilities/world_report/2011/report.pdf

\section{CONTRIBUTOR INFORMATION}


Jackie Leach Scully is a professor of social ethics and bioethics, and Executive Director of the Policy, Ethics and Life Sciences Research Centre at Newcastle University, UK. She is a Fellow of the Academy of Social Sciences. 